\title{
Ionic Liquid Pretreatment of Rice Straw to Enhance Saccharification and Bioethanol Production
}

\author{
Nafiseh Poornejad ${ }^{1 *}$, Keikhosro Karimi1 ${ }^{1,2}$, Tayebeh Behzad ${ }^{1}$ \\ ${ }^{1}$ Department of Chemical Engineering, Isfahan University of Technology, \\ Isfahan 84156-83111, Iran \\ n.poornejad@ce.iut.ac.ir \\ 2 Industrial Biotechnology Group, Institute of Biotechnology and Bioengineering, \\ Isfahan University of Technology, Isfahan 84156-83111, Iran
}

\begin{abstract}
In this study, rice straw was pretreated by an ionic liquid, 1-ethyl-3-methylimidazolium acetate ([EMIM][OAc]), prior to enzymatic hydrolysis and ethanol production. The pretreatment was carried out at $120{ }^{\circ} \mathrm{C}$ for $5 \mathrm{~h}$ under atmospheric pressure. Afterward, saccharification was conducted at $45^{\circ} \mathrm{C}$ for $72 \mathrm{~h}$ using $20 \mathrm{FPU}$ cellulase and $30 \mathrm{IU} \beta$ glucosidase per gram of cellulose. Glucose yield was significantly increased from $25.7 \%$ for the untreated straw to over $75 \%$ for the treated straw. Moreover, the ethanol yield by simultaneous saccharification and fermentation was improved from $35.6 \%$ for the untreated straw to $79.7 \%$ for the treated straw. SEM images showed more open and accessible structure for the treated straw compared to the untreated one which assisted the penetration of hydrolytic enzymes in the saccharification and fermentation. From FTIR analysis, it was suggested that the crystallinity reduction and conversion of cellulose I to II are the main changes in the straw as a result of the pretreatment.
\end{abstract}

Keywords: [EMIM][OAc], Ethanol, Ionic liquid, pretreatment, rice straw.

(C) Copyright 2014 Authors - This is an Open Access article published under the Creative Commons Attribution License terms http://creativecommons.org/licenses/by/3.0). Unrestricted use, distribution, and reproduction in any medium are permitted, provided the original work is properly cited.

\section{Introduction}

Recently, lignocellulosic biomasses attract great attention of scientists as a potential feedstock for bioethanol production. Lignocelluloses are widely available in different waste sources such as municipal, agricultural, and forestry residues, and they mainly consist of cellulose, hemicelluloses, and lignin [1]. Cellulose and hemicellulose can be both enzymatically or chemically hydrolyzed to reduced sugar units and further fermented to ethanol. However, complex structure, lignin strong linkage, hydrogen bonds between cellulose chains, and highly crystalline cellulose structure cause these materials to be very resistance to both chemical and enzymatic hydrolysis [1-3]. Therefore, for economically feasible ethanol production, an effective pretreatment step should be applied to improve the saccharification yield.

By now, various chemical, physical, biological, and combined pretreatment methods have been employed. The most common methods are alkali or acid pretreatments [4, 5], ammonia fiber explosion [6], steam or carbon dioxide explosion [7, 8], and liquid hot water pretreatment [9]. However, majority of these methods need high temperatures and pressures or harsh acidic or basic conditions. Therefore, they are not environmentally friendly and require high amount of energy [10]. Recently, to overcome these drawbacks, researchers have attempted to use a new class of cellulose solvents called ionic liquids. Ionic liquids are organic salts that are liquid at room temperature [11]. These materials have some priorities over the conventional solvents including being more environmentally benign, requiring less process time, and being more efficient [12].In addition, the processing conditions of ionic liquids are mild, and their recycling efficiency is over 99\% [10]. Cellulose regenerated by ionic liquids is less crystalline and more amenable to enzymatic hydrolysis [13].

Among the various ionic liquids, 1-Butyl-3methylimidazolium chloride ([BMIM]Cl), 1-Ethyl-3methylimidazolium hydroxide ([EMIM]OH), and -ethyl3-methylimidazolium acetate ([EMIM][OAc]) have 
superior cellulose solubility characteristic. However, the ionic liquids involving $\mathrm{Cl}^{-}$and $\mathrm{OH}$-are corrosive and can adversely affect the enzymes activity resulting in lower overall hydrolysis yield. [EMIM]][OAc] is among the best cellulose solvents in terms of solubility characterization and compatibility with hydrolytic enzymes. Furthermore, it is an environmentally friendly ionic liquid [14]. Because of these attractive properties, it has been suggested as an effective chemical for lignocelluloses pretreatment to improve hydrolysis and ethanol production $[15,16]$.

Rice straw is one of the most available lignocelluloses residues in all over the world. Several previous studies have attempted to improve its digestibility to reduced sugar units applying different pretreatment methods such as microwave pretreatment $[17,18]$, electron beam irradiation [19], and dilute acid hydrolysis [20]. In a recent study, Feng [21] used an ionic solvent, $[\mathrm{AMIM}] \mathrm{Cl}$, to treat the straw at $110{ }^{\circ} \mathrm{C}$. He succeeded to improve the hydrolysis yield from $23.7 \%$ for the untreated straw to $53.3 \%$ for the pretreated one. However, to our knowledge, no previous work has been done on pretreatment of rice straw by [EMIM][OAc].

The main goal of this study is to enhance bioethanol production of rice straw by applying [EMIM][OAc] pretreatment. Enzymatic hydrolysis and simultaneous saccharification and fermentation were performed to evaluate the pretreatment effect. The compositional and structural properties of the pretreated straw were also studied by different analyses.

\section{Materials and Methods}

\subsection{Materials and Microorganism}

The rice straw used in this study was obtained from Lenjan field (Isfahan, Iran). Before experiments, its size was reduced from about $50 \mathrm{~mm}$ to less than $0.853 \mathrm{~mm}$ (mesh 20) and then dried at $40{ }^{\circ} \mathrm{C}$ for $24 \mathrm{~h}$. The solid content of straw was measured after drying at $105^{\circ} \mathrm{C}$ until a constant weight was achieved.

A commercially available ionic liquid, 1-ethyl-3methylimidazolium acetate ([EMIM][OAc]), was purchased from Sigma-Aldrich provided by BASF (Ludwigshafen, Germany).

A fluctuation of Saccharomyces cerevisiae (CCUG 53310, Culture Collection of University of Gothenburg, Sweden) was used as a fermenting microorganism. The microorganism maintenance and its biomass production was conducted according to the method presented by Karimi et al. [22].

\subsection{Pretreatment Procedure}

A suspension of rice straw in the ionic liquid with $5 \%$ solid loading were prepared in a $200 \mathrm{ml}$ beaker in an oil bath at $120{ }^{\circ} \mathrm{C}$ and pretreated for $5 \mathrm{~h}$. The pretreatment conditions were selected based on optimized parameters obtained in a previous research [23].The suspension was mixed every $15 \mathrm{~min}$ by a glass rode to ensure complete distribution of solid in the solvent. At the end of the pretreatment, the dissolved solid was regenerated by sudden addition of $30 \mathrm{ml}$ boiling water. The precipitated solid was recovered by vacuum filtration and washed by ethanol and boiling water till clear filtrate was achieved. The straw was then dried at $40^{\circ} \mathrm{C}$ for three days, and then stored in sealed bags for further use and analysis.

\subsection{Enzymatic Hydrolysis}

Cellulase (Celluclast 1.5L, Novozyme, Denmark) and $\beta$-glucosidase (Novozyme 188, Novozyme, Denmark) enzymes were used for the hydrolysis. The activity of cellulase was $60 \mathrm{FPU} / \mathrm{ml}$ (measured according to Adney and Baker (1996) procedure and that of $\beta$-glucosidase was $190 \mathrm{IU} / \mathrm{ml}$ (measured by the method presented by Ximenes et al. [24]1996).

Enzymatic hydrolysis of all treated and untreated straws was carried out in $100 \mathrm{ml}$ bottles containing 30 $\mathrm{ml}$ media of $50 \mathrm{mM}$ sodium citrate buffer $(\mathrm{pH} \mathrm{4.8)}$ and $10 \mathrm{~g} / \mathrm{l}$ substrate loading. Then 20 FPU cellulase and 30 IU $\beta$-glucosidase per gram of substrate and $0.5 \mathrm{~g} / \mathrm{l}$ sodium azide were added to each bottle. The hydrolysis was conducted in a shaker incubator with the speed of $100 \mathrm{rpm}$ at $45^{\circ} \mathrm{C}$ for $72 \mathrm{~h}$. Liquid samples were periodically taken and analyzed for the released sugar.

\subsection{Simultaneous Saccharification and Fermentation (SSF)}

A fluctuation of Saccharomyces cerevisiae (CCUG 53310, Culture Collection of University of Gothenburg, Sweden) was used as a fermenting microorganism. The treated and untreated straws were subjected to simultaneous saccharification and fermentation at $38^{\circ} \mathrm{C}$ under anaerobic conditions for $48 \mathrm{~h}$ in a shaker incubator at $80 \mathrm{rpm}$. A media containing $5 \mathrm{~g} / \mathrm{l}$ yeast extract, $7.5 \mathrm{~g} / \mathrm{l}\left(\mathrm{NH}_{4}\right)_{2} \mathrm{SO}_{4}, 3.5 \mathrm{~g} / \mathrm{l} \mathrm{K}_{2} \mathrm{HPO}_{4}, 0.75 \mathrm{~g} / \mathrm{l}$ $\mathrm{MgSO}_{4} \cdot 7 \mathrm{H}_{2} \mathrm{O}, 1 \mathrm{~g} / \mathrm{l} \mathrm{CaCl}_{2} \cdot 2 \mathrm{H}_{2} \mathrm{O}$, and $50 \mathrm{~g} / \mathrm{l}$ pretreated or untreated rice straw was prepared in $0.05 \mathrm{M}$ buffer citrate ( $\mathrm{pH} 5)$. After sterilization at $121{ }^{\circ} \mathrm{C}$ for $20 \mathrm{~min}$ and cooling to room temperature, $1 \mathrm{~g} / \mathrm{l}$ S. cerevisiae and $20 \mathrm{FPU}$ cellulase and $30 \mathrm{IU} \beta$-glucosidase per gram of substrate were added to the mixture and incubated for 
48 h. Liquid samples were taken, centrifuged, and analyzed for metabolite and sugar analyses.

The theoretical yield of ethanol production was calculated based on the glucose that can be produced supposedly from the glucan in the treated or nontreated rice straw while the glycerol yield was reported as milligrams of produced glycerol per gram of the theoretical glucose [22].

\subsection{Analytical Methods}

Ethanol and glycerol contents in the liquid samples obtained by simultaneous saccharification and fermentation as well as various sugar contents (glucose, xylose, arabinose, mannose, and galactose) were analyzed by high-performance liquid chromatography (HPLC) equipped with UV/vis and RI detectors (Jasco International Co., Tokyo, Japan). Ethanol and glycerol were analyzed on an Aminex HPX-87H column (BioRad, Richmond, CA, USA) at $60{ }^{\circ} \mathrm{C}$ with $0.6 \mathrm{ml} / \mathrm{min} 5$ $\mathrm{mM}$ sulfuric acid as an eluent. In addition, sugars were analyzed on an ion-exchange Aminex HPX-87P column (Bio-Rad, USA) at $85{ }^{\circ} \mathrm{C}$ with deionized water as a mobile phase with the flow rate of $0.6 \mathrm{ml} / \mathrm{min}$.

To analyze carbohydrate and lignin contents of the biomass, an standard method presented by National Renewable Energy Laboratory (NREL) was employed [25]. The carbohydrates were hydrolyzed to the corresponding sugars and analyzed by HPLC. Lignin was classified into acid-insoluble and soluble materials. The acid-soluble lignin was measured by UV-vis spectroscopy at $240 \mathrm{~nm}$ with absorptivity of $25 \mathrm{l} / \mathrm{g} . \mathrm{cm}$. The acid-insoluble part was determined as a part of solid collected by filtration after the hydrolysis.

FTIR reflectance spectra of untreated and treated straws were collected within wave numbers of 600 to $4,000 \mathrm{~cm}^{-1}$ with $4 \mathrm{~cm}^{-1}$ resolution using a Fourier transform infrared (FTIR). The spectrometer was equipped with a universal ATR (Attenuated Total Reflection) accessory and Deuteratedtriglycine sulfate (DTGS) detector (Bruker Tensor 27 FT-IR). Their spectra were obtained with an average of 60 scans.

Scanning electron microscopy (SEM) images of untreated and treated straws were obtained to analyze morphological effect of the pretreatment step. Dried treated and untreated straw were coated with gold (BAL-TEC SCD 005) and analyzed by SEM (PHILIPS, $\mathrm{XL30)}$ at $15 \mathrm{kV}$.

All experiments were done at least in duplicate and the reported results are the average of obtained values. The error bars on reported figures are the range of higher and lower values obtained for each point showing the range of validity of the results.

\section{Results and Discussion}

Rice straw, one of the most abundant lignocellulosic wastes, was subjected to a solvent pretreatment using [EMIM][OAc] at its optimum treatment conditions which is $120^{\circ} \mathrm{C}$ for $5 \mathrm{~h}$ [26-28].

\subsection{Enzymatic Hydrolysis}

In order to examine the effect of pretreatment on rice straw saccharification, enzymatic hydrolysis of all treated and untreated straw was done for $72 \mathrm{~h}$ at $45{ }^{\circ} \mathrm{C}$ using cellulase and $\beta$-glucosidase enzymes. Glucose and xylose yields of hydrolysis of the treated straw were significantly improved and summarized in Table 1 and Figure 1, respectively.

Table 1. Hydrolysis and fermentation results of pretreated and untreated rice straw.

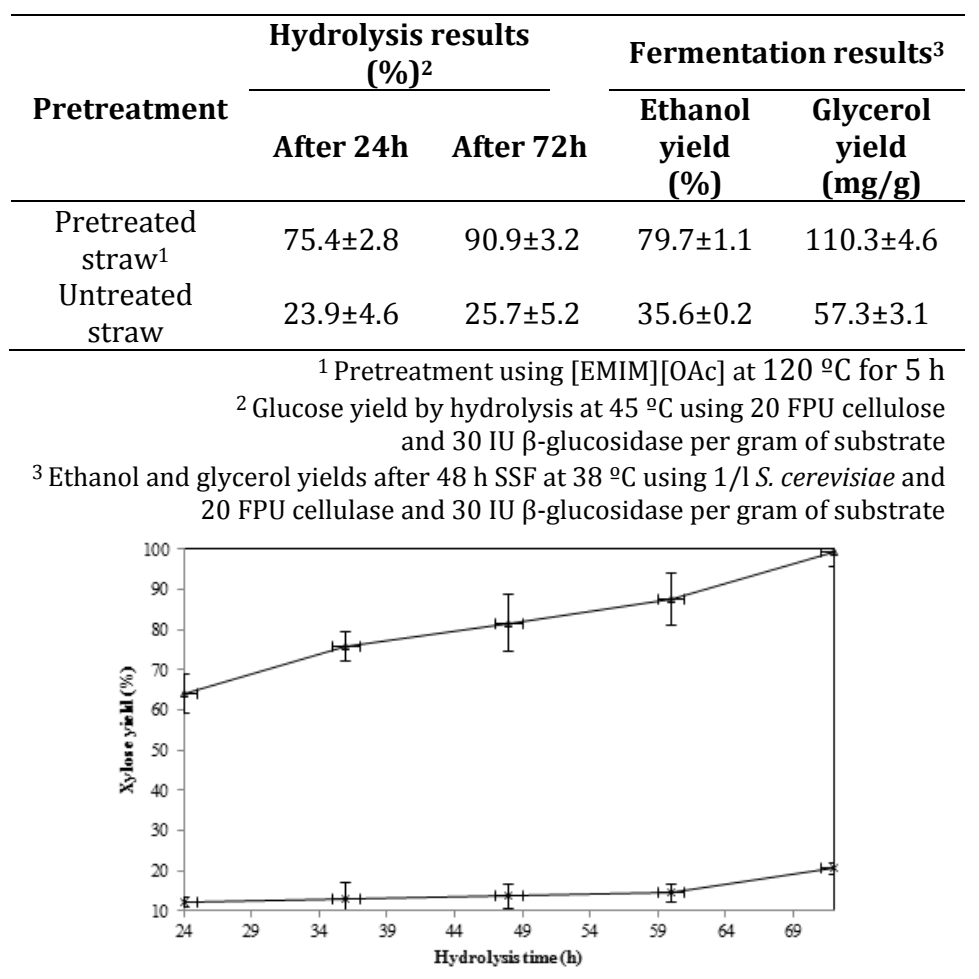

Figure 1. Xylose hydrolysis yield for untreated rice straw and the straw treated with [EMIM] [OAc] for $5 \mathrm{~h}$ at $120^{\circ} \mathrm{C}$ (upper curve for treated straw and the lower for untreated one).

The major hydrolysis was obtained after $24 \mathrm{~h}$ hydrolysis, and prolongation of the hydrolysis to $72 \mathrm{~h}$ showed a minor improvement (Table 1). Xylose is another product of hydrolysis comes from hemicelluloses hydrolysis. The pretreatment 
significantly improved the yield of xylan hydrolysis (Figure 1). According to obtained data, hydrolysis rate at the first $24 \mathrm{~h}$ was significantly higher for treated straw compared to the untreated one. Moreover, the same trend was observed after $72 \mathrm{~h}$ hydrolysis. These results confirm the possibility of the claim that ionic pretreatment step can efficiently improve the straw digestibility in the hydrolysis step.

The results are in line of the results obtained by Shafiei et al. [29] on pretreatment of spruce wood powder by the same ionic liquid. They showed that prolongation of the pretreatment time from $3 \mathrm{~h}$ to $15 \mathrm{~h}$ did not positively affect the yield of hydrolysis. Furthermore, it was shown that using the pretreatment at high temperature of $120^{\circ} \mathrm{C}$ is more effective than the pretreatment with [EMIM][OAc] at lower temperature even for a very long time (i.e., at $90{ }^{\circ} \mathrm{C}$ for 24 or $70 \mathrm{~h}$ ) [16].

\subsection{Simultaneous Saccharification and Fermentation (SSF)}

Ethanol was produced by SSF at $38{ }^{\circ} \mathrm{C}$ for $48 \mathrm{~h}$ in the presence of cellulase, $\beta$-glucosidase, and $S$. cerevisiae for the untreated and pretreated straw and results are reported in Table 1 . As it can be noticed from the data, the ethanol yield was improved from $35 \%$ to $79 \%$ which indicates the great impacts of the pretreatment. The results of rice straw pretreatment by [EMIM][OAc]are comparable with the results of wheat straw pretreated by [EMIM]DEP [13], a similar ionic liquid with different anionic group. The observed results could be predicted from the fact that the opened up structure and more accessible substrate to the hydrolytic enzymes can have a dramatic positive effect on the digestibility of cellulose which followed by more efficient conversion to the final product.

Glycerol is the major byproduct of ethanol production, and its production improvement by the pretreatment is compatible with the ethanol yield enhancement. Glycerol yield was improved from 57.3 $\mathrm{mg} / \mathrm{g}$ for untreated straw to $110.3 \mathrm{mg} / \mathrm{g}$ of glucose for treated one which shows about 100\% improvement.

\subsection{Compositional Analysis}

To investigate and justify the origin of the observed improvement, the structural composition of treated and untreated straw, supposed to have the most significant importance on hydrolysis, was determined, and the results are shown in Figure 2. As it can be concluded from the results, glucan content of the regenerated solid was increased compared with that of untreated straw which indicates more purified cellulose resulted in more efficient hydrolysis of the pretreated solid. On the other hand, xylan, resulted from the hydrolysis of hemicelluloses, was reduced by the pretreatment. Moreover, lignin, the most important obstacle for enzymatic hydrolysis of lignocellulosic materials, was reduced in precipitated solid in comparison with the untreated straw. Lignin and hemicelluloses are both responsible for recalcitrance of lignocelluloses which were decreased due to solubilization in the ionic liquid and not precipitation during regeneration (addition of the anti-solvent). The hemicellulose and lignin removal leads to a higher concentration and more accessible cellulose, which improved the yield of hydrolysis and ethanol production. There is also a minor change in ash content of the straw as a result of the pretreatment.

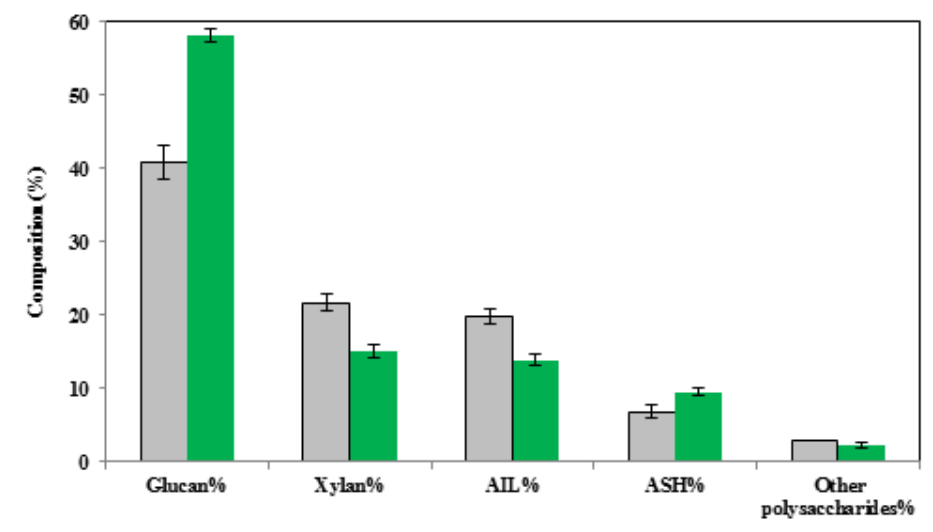

Figure 2. Composition of untreated rice straw (gray color) and the straw treated with [EMIM][OAc] at $120^{\circ} \mathrm{C}$ for $5 \mathrm{~h}$ (green color).

As discussed in the hydrolysis result section, it could be predicted that increasing pretreatment retention time at high temperature (more than $100{ }^{\circ} \mathrm{C}$ ) may cause some degradation effect on cellulose and hemicelluloses; however, cellulose percent is still increased. The degradation of glucan and xylan at 130 o $C$ was proved by Lee et al. [16]. In addition, the lignin removal effect of ionic liquid treatment was also observed by several previous studies [16, 30-32].

\subsection{Change in the Morphology of Rice Straw by Pretreatment}

Morphology of the pretreated and untreated straw was analyzed by SEM images (Figure 3). One of the main obstacles, or maybe the most effective one, for the 
digestibility of straw is crystalline and organized structure of the cellulosic fibers. As could be seen in SEM images, the organized structure of the straw is completely destroyed as a result of the pretreatment. Therefore, the structure of the straw was changed from a compact and unavailable form to an open up and widely accessible form. This could assist and accelerate the penetration of the enzymes to the carbohydrates. Also, there are some fine spots on the untreated straw which disappear on the treated one. These spots are silica which is one of the problematic component of rice straw in both its storage and conversion. Removal of this component as a result of the pretreatment is another possible reason for improvement of enzymatic hydrolysis.

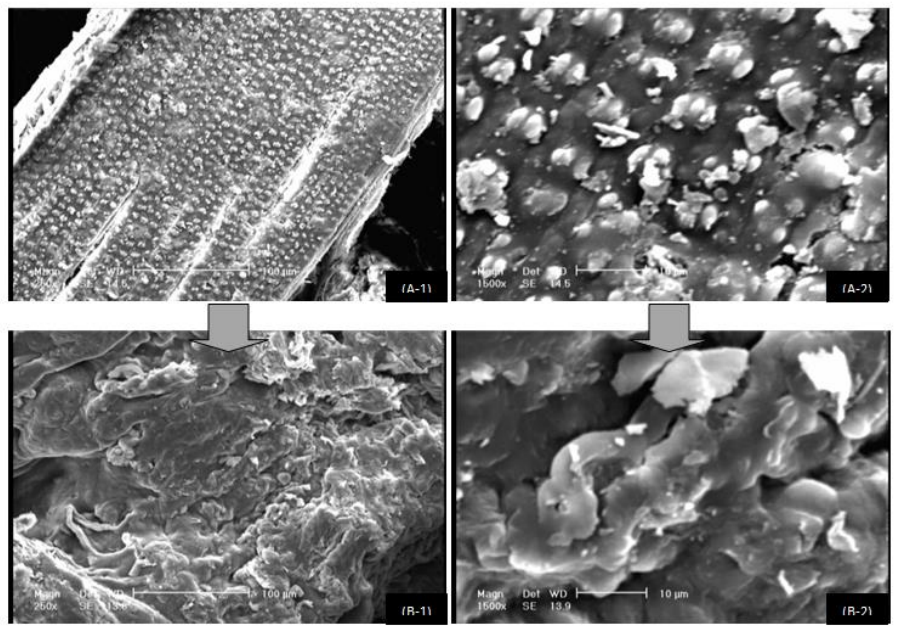

Figure 3. SEM images of native straw (A) and pretreated straw (B).

To evaluate the pretreatment effect on cellulose crystallinity of straw, FTIR analysis of the treated and untreated straw was conducted. FTIR spectra and absorbance data are presented in Figure 4 and Table 2, respectively.

Table 2. Characteristic and variation of bands in FTIR spectra of the untreated rice straw and the straw treated with [EMIM][OAc] for $5 \mathrm{~h}$ at $120^{\circ} \mathrm{C}$.

\begin{tabular}{ccccc}
\hline $\begin{array}{c}\text { Wavenumber } \\
\left(\mathbf{c m}^{-1} \mathbf{)}\right.\end{array}$ & Functional group & Assignment & Untreated straw & $\begin{array}{c}\text { Treated straw } \\
\text { for 5 h }\end{array}$ \\
\hline 3175 & -OH stretching intramolecular hydrogen bonds & Cellulose II & 0.1 & 0.17 \\
2918 & C-H stretching & Cellulose & 0.11 & 0.16 \\
1730 & C=O stretching of acetyl or carboxylic acid & Hemicellulose \& lignin & 0.07 & 0.05 \\
1627 & C=C stretching of the aromatic ring & Lignin & 0.17 & 0.12 \\
1598 & C=C & Lignin & 0.14 & 0.09 \\
1510 & C=C stretching of the aromatic ring & Lignin & 0.1 & 0.1 \\
1465 & Asymmetric bending in C-H3 & Lignin & 0.13 & 0.11 \\
1423 & C-H2 symmetric bending & Cellulose & 0.17 & 0.2 \\
1430 & C-H2 bending & Cellulose I & 0.17 & 0.19 \\
1375 & C-H bending & Cellulose & 0.18 & 0.24 \\
1335 & -OH (in plane bending) & Cellulose & 0.18 & 0.21 \\
1315 & C-H2 wagging & Cellulose & 0.21 & 0.22 \\
1158 & C-O-C asymmetric stretching & Cellulose & 0.42 & 0.39 \\
896 & Asym., out of phase ring stretching (cellulose) & Cellulose II & 0.36 & 0.49 \\
\hline
\end{tabular}




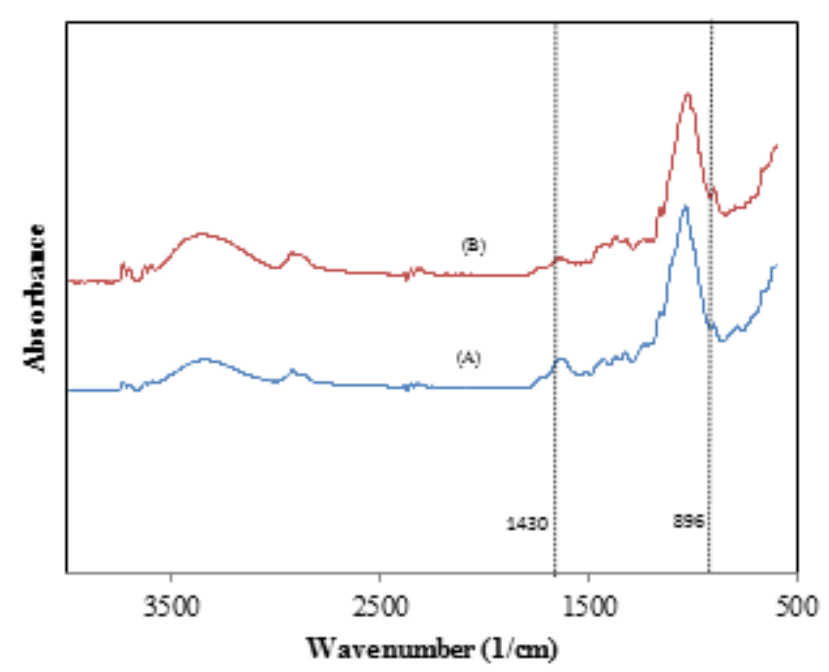

Figure 4. FTIR spectra of native straw (A) and treated straw (B).

The absorption bands at $1430 \mathrm{~cm}^{-1}$ represents crystalline cellulose I, while the band at $898 \mathrm{~cm}^{-1}$ is assigned to the cellulose II and amorphous cellulose which is more amenable to enzymatic hydrolysis [33]. The results showed that cellulose I in the native straw was changed to cellulose II as a result of the pretreatment. Furthermore, the absorption ratio at absorption bands of 1430 and $896 \mathrm{~cm}^{-1}$, referred to as crystallinity index (CI) [33], was used for evaluation of crystallinity reduction due to the pretreatment. This value for untreated straw and treated straw was 0.47 and 0.38, respectively. Moreover, another index for crystallinity evaluation is total crystallinity index (TCI), the ratio of absorption bands at 1975 and $2918 \mathrm{~cm}^{-1}$, was obtained to be 1.6 and 1.5 for the untreated and treated straws, respectively. As indicated by both $\mathrm{CI}$ and TCI calculations, majority of crystalline cellulose was modified to amorphous and less crystalline regions which are amenable to enzymatic attack.

\subsection{Mass Balance}

Overall mass balance for pretreatment, hydrolysis, and simultaneous saccharification and fermentation step was presented in Table 3. As stated by the observed data, each ton of pretreated rice straw can produce $450 \mathrm{~kg}$ glucose and $250 \mathrm{~L}$ ethanol. However, these values for untreated straw are only $120 \mathrm{~kg}$ and $100 \mathrm{~L}$, respectively. Reported by FAO, the worldwide rice production in 2012 was 724.5 million tons. On average, 1-1.5 kg straw is produced per kg of rice [34] which results in production of 900 million tons rice straw annually. According to the results of current study, this amount of straw has a potential to produce 225 billion liters ethanol per year.

Table 3. Overall mass balance over pretreatment, hydrolysis, and simultaneous saccharification and fermentation for untreated and pretreated rice straw.

\begin{tabular}{lcc}
\hline Substrate & $\begin{array}{c}\text { Untreated } \\
\text { straw }\end{array}$ & $\begin{array}{c}\text { Pretreated } \\
\text { straw }\end{array}$ \\
\hline $\begin{array}{l}\text { Grams of solid recovered after } \\
\text { pretreatment per } 100 \text { grams of }\end{array}$ & - & $73 \pm 2.1$ \\
initial straw & & \\
$\begin{array}{l}\text { Grams of glucose obtained after } \\
72 \text { h hydrolysis per } 100 \text { grams of }\end{array}$ & $11.7 \pm 1.8$ & $44.3 \pm 3.9$ \\
$\begin{array}{l}\text { initial straw } \\
\text { Grams of ethanol released after } \\
48 \text { h SSF per } 100 \text { grams of initial } \\
\text { straw }\end{array}$ & $8.3 \pm 1.3$ & $19.2 \pm 2.4$ \\
\hline
\end{tabular}

\section{Conclusions}

Pretreatment of rice straw using ionic liquid [EMIM][OAc] can be considered as a promising alternative to improve the enzymatic digestibility and ethanol production. Pretreatment of rice straw at 120 ${ }^{\circ} \mathrm{C}$ for $5 \mathrm{~h}$ can improve the yield of ethanol production by $75 \%$. More accessible morphology, less crystallinity, lower lignin and hemicelluloses concentrations are the main reasons for the improvements.

\section{Acknowledgment}

The authors are grateful to Institute of Biotechnology and Bioengineering, Isfahan University of Technology for financial support of this work.

\section{References}

[1] M.J. Taherzadeh and K. Karimi, "Pretreatment of lignocellulosic wastes to improve ethanol and biogas production: A review", International Journal of Molecular Sciences, 9(9), 2008, 16211651.

[2] A.T.W.M. Hendriks and G. Zeeman, "Pretreatments to enhance the digestibility of lignocellulosic biomass" Bioresource Technology, 100(1), 2009, 10-18.

[3] N. Mosier, Ch. Wyman, B. Dale, R. Elander, Y.Y. Lee, M. Holtzapple, M. Ladisch, "Features of promising technologies for pretreatment of lignocellulosic biomass", Bioresource Technology, 96(6), 2005, 673-86. 
[4] Z. Hu and Z. Wen, "Enhancing enzymatic digestibility of switchgrass by microwaveassisted alkali pretreatment", Biochemical Engineering Journal, 38(3), 2008, 369-378.

[5] B.C. Saha, L.B. Iten, M.A. Cotta, V. Wu, "Dilute acid pretreatment, enzymatic saccharification and fermentation of wheat straw to ethanol", Process Biochemistry, 40(12), 2005, 3693-3700.

[6] H. Alizadeh, F. Teymouri, T. Gilbert, B. Dale, "Pretreatment of switchgrass by ammonia fiber explosion (AFEX)", Applied Biochemistry and Biotechnology, 124(1-3), 2005, 1133-1141.

[7] M.J. Negro, P. Manzanares, J.M. Olivia, I. Ballesteros, M. Ballesteros, "Changes in various physical/chemical parameters of Pinus pinaster wood after steam explosion pretreatment", Biomass and Bioenergy, 25(3), 2003, 301-308.

[8] V.P. Puri and H. Mamers, "Explosive pretreatment of lignocellulosic residues with high-pressure carbon dioxide for the production of fermentation substrates", Biotechnology and Bioengineering, 25(12), 1983, 3149-3161.

[9] Q. Yu, Y. Zhuang, Q. Wang, W. Qi, W. Wang, Y. Zhang, J. Xu, H. Xu, "Two-step liquid hot water pretreatment of Eucalyptus grandis to enhance sugar recovery and enzymatic digestibility of cellulose", Bioresource Technology, 101(13), 2010, 4895-4899.

[10] P. Mäki-Arvela, I. Anugwom, R. Sjoholm, J.P. Mikkola, "Dissolution of lignocellulosic materials and its constituents using ionic liquids-A review", Industrial Crops and Products, 32(3), 2010, 175201.

[11] H. Zhao, C. Jones, G. Baker, Sh. Xia, O. Olubajo, V.N. Person, "Regenerating cellulose from ionic liquids for an accelerated enzymatic hydrolysis", Journal of Biotechnology, 139(1), 2009, 47-54.

[12] D. Fu and G. Mazza, "Aqueous ionic liquid pretreatment of straw", Bioresource Technology, 102(13), 2011, 7008-7011.

[13] Q. Li, B. Knierima, Ch. Manisseri, R. Arora, H.V. Scheller, M. Auer, K.P. Vogel, A. Simmons, S. Singh "Improving enzymatic hydrolysis of wheat straw using ionic liquid 1-ethyl-3-methyl imidazolium diethyl phosphate pretreatment", Bioresource Technology, 100(14), 2009, 3570-3575.

[14] L. Li, S-T. Yu, F-S. Liu, C-X. Xie, C-Z. Xu "Efficient enzymatic in situ saccharification of cellulose in aqueous-ionic liquid media by microwave pretreatment", Bioresources, 6(4), 2011, 11.
[15] T.N. Ang, L.W. Yoon, K.M. Lee, G.C. Ngoh, A.S.M. Chua, M.G. Lee, "Efficiency of ionic liquids in the dissolution of rice husk", Bioresources, 6(4), 2011, 10.

[16] S.H. Lee, Th. V. Dohrety, R.J. Linhardt, J.S. Dordik, "Ionic liquid-mediated selective extraction of lignin from wood leading to enhanced enzymatic cellulose hydrolysis", Biotechnology and Bioengineering, 102(5), 2009, 1368-1376.

[17] S. Zhu, Y. Wu, Z. Yu, C. Wang, F. Yu, S. Jin, Y. Ding, R. Chi, J. Liao, Y. Zhang, "Comparison of three microwave/chemical pretreatment processes for enzymatic hydrolysis of rice straw", Biosystems Engineering, 93(3), 2006, 279-283.

[18] G. Gong, D. Liu, and Y. Huang, "Microwaveassisted organic acid pretreatment for enzymatic hydrolysis of rice straw", Biosystems Engineering, 107(2), 2010, 67-73.

[19] J.S. Bak, J.K. Ko, Y. Han, B.Ch. Lee, I. Choi, K. Kim, "Improved enzymatic hydrolysis yield of rice straw using electron beam irradiation pretreatment", Bioresource Technology, 100(3), 2009, 1285-1290.

[20] K. Karimi, S. Kheradmandinia, and M.J. Taherzadeh, "Conversion of rice straw to sugars by dilute-acid hydrolysis", Biomass \& Bioenergy, 30(3), 2006, 247-253.

[21] H.S. Hong Feng, "Biorefinery of bacterial cellulose from rice straw: enhanced enzymatic saccharification by ionic liquid pretreatment", Engineering science, 9(4), 2011, 4.

[22] K. Karimi, G. Emtiazi, and M.J. Taherzadeh, "Ethanol production from dilute-acid pretreated rice straw by simultaneous saccharification and fermentation with Mucor indicus, Rhizopus oryzae, and Saccharomyces cerevisiae", Enzyme and Microbial Technology, 40(1), 2006, 138-144.

[23] N. Poornejad, "Improved Saccharification and Fermentation of Rice Straw using Various Solvents for Pretreatment Step", in Chemcial Engineering, Isfahan University of Technology: Isfahan, 2012, p. 90.

[24] E.A. Ximenes, C.R. Felix, and C.J. Ulhoa, "Production of cellulases by Aspergillus fumigatus and characterization of one b-glucosidase", Current Microbiology, 32(3), 1996, 119-23.

[25] A. Sluiter, B. Hames, C. Ruiz, J. Sluiter, D. Templeton, D. Crocker, "Determination of Structural Carbohydrates and Lignin in Biomass", 
Laboratory Analytical Procedure, NREL/TP-51042618, 2008.

[26] H. Xie, S. Li, S. Zhang, "Ionic liquids as novel solvents for the dissolution and blending of wool keratin fibers", Green Chemistry, 7(7), 2005, 3.

[27] A.P. Dadi, S. Varanasi, and C.A. Schall, "Enhancement of cellulose saccharification kinetics using an ionic liquid pretreatment step", Biotechnology Bioengineering, 95(5), 2006, 90410.

[28] J. Wu, J. Zhang, H. Zhang, J. He, Q. Ren, M. Gue, "Homogeneous Acetylation of Cellulose in a New Ionic Liquid", Biomacromolecules, 5(2), 2004, 266-268.

[29] M. Shafiei, H. Zilouei, A. Zamani, M.J. Taherzafeh, K. Karimi, "Enhancement of ethanol production from spruce wood chips by ionic liquid pretreatment", Applied Energy, 102, 2013, 163169.

[30] D.A. Fort, R.C. Remsing, R.P. Swatloski, P. Moyna, G. Moyna, R.D. Rogers, "Can ionic liquids dissolve wood? Processing and analysis of lignocellulosic materials with 1-n-butyl-3-methylimidazolium chloride", Green Chemistry. 9(1), 2007, 63-69.

[31] J.B. Binder, M.J. Gray, J.F. White, C. Zhang, J.E. Holladay, "Reactions of lignin model compounds in ionic liquids", Biomass and Bioenergy, 33(9), 2009, 1122-1130.

[32] N. Sun, M. Rahman, M.L. Maxim, H. Rodriguez, R.D. Rogers, "Complete dissolution and partial delignification of wood in the ionic liquid 1-ethyl3-methylimidazolium acetate", Green Chemistry, 11(5), 2009, 646-655.

[33] D.C. Nieves, K. Karimi, and I.S. Horváth, "Improvement of biogas production from oil palm empty fruit bunches (OPEFB)", Industrial Crops and Products, 34(1), 2011, 1097-1101.

[34] P. Binod, N. Kurien, R.K. Sukumaran, A. Pandey, "Bioethanol production from rice straw: An overview", Bioresource Technology, 101(13), 2010, 4767-74. 